\title{
The Investigation of Predictive Relationships between Loneliness, Internet Addiction, and Mindfulness through the Structural Equation Model
}

\author{
Mehmet Murat \\ Faculty of Education, Gaziantep University, Turkey
}

Copyright $(2019$ by authors, all rights reserved. Authors agree that this article remains permanently open access under the terms of the Creative Commons Attribution License 4.0 International License

\begin{abstract}
Objective: The aim of this study is to examine the predictive relationships between loneliness, Internet addiction, and mindfulness. Method: The study group consisted of 507 university students studying at Gaziantep University. Of the participants, 352 (69.4\%) were female and $155(30.6 \%)$ were male. UCLA Loneliness Scale, Internet Addiction Scale, and Mindfulness Scale were used for data collection. Firstly, the normal distribution of data is examined. Then correlation analysis on loneliness was conducted in order to determine the relationship between Internet addiction and mindfulness. The structural equation was used to measure loneliness in order to determine the predictive relationship between Internet addiction and mindfulness. Results: The results of the study showed that loneliness was negatively correlated with mindfulness, and there was a positive correlation that Internet addiction and mindfulness have a negative relationship with Internet addiction. According to the structural equation model, it was observed that loneliness predicted Internet addiction in a positive way and mindfulness in a negative way. Mindfulness predicts Internet addiction in a negative way. The loneliness has also been found to have an indirect effect on Internet addiction via the mindfulness variable.
\end{abstract}

Keywords Loneliness, Internet Addiction, Internet Use, Mindfulness

\section{Introduction}

Nowadays, the Internet has become an interest to researchers due to the excessive use of the Internet and the increasing use rising in addictive levels [1, 2]. Internet addiction can be expressed as the excessive use of devices and technologies that may be associated with the Internet. It is clear that the Internet, which is used frequently, can adversely affect people.
According to studies, the loneliness of the Internet [3-5], depression [6-7], psychiatric symptoms [8], shyness [9], stress [10] are variables related to the positive direction that is associated with the increase in the level of Internet addiction and the said variables may also increase. Kim, LaRose, and Peng [11] have expressed that variables such as loneliness and depression with study individuals could prove to be fixed causes with Internet usage and could push compulsive levels so that it would be used more. It also plays into satisfaction and compensates for the loneliness scores, which were expressed as life predictors of Internet usage. However, the same researchers stated that there is not a significant relationship between loneliness and social objectives when the Internet and social media are used with applications where people can express their thoughts. In another study in which the relationship between Internet addiction and loneliness was examined, it was reported that high levels of Internet usage was associated with low levels of social loneliness and high levels emotional loneliness. Based on these results, it is stated that even if the Internet is used for communication purposes, it can negatively affect the social well-being of individuals [12]. In a study that examined the relationship between Internet addiction and loneliness in adolescents and children, it was stated that loneliness predicted Internet addiction [13]. In another study in which the relationships between depression, loneliness, Internet addiction, and low will-level were examined with a structural equation model, it was reported that loneliness was positively related to Internet addiction and predicted Internet addiction over low will [14]. Similarly, Zhang et al. [15] reported that loneliness predicts compulsive Internet use positively.

Here, it can be concluded from the mentioned research that loneliness may cause Internet addiction. As a matter of fact, these researchers mention that loneliness may cause an excessive use of the Internet. However, when the related literature is examined, it is seen that there are contradictory findings and thoughts. For example, Shaw and Gant [16] tested depression, the Internet, loneliness, perceived social 
support, and self-esteem. First of all, the participants were able to communicate and chat with people they did not know during the five sessions. Later, measurements showed that Internet usage significantly decreased loneliness and depression levels compared to the pre-study scores of the participants. In another study, it was reported that individuals could use the Internet to deal with loneliness and that only these individuals use the Internet and e-mail more and that they are seeking more emotional support on the Internet [17]. In a study that examined the effects of sharing photos on loneliness, shyness, narcissism, and social anxiety on Facebook, it was concluded that the time spent on Facebook poses a positive relationship with narcissism but it affects loneliness and shyness negatively [18]. In parallel with the research studies mentioned here, there are studies that indicate that Internet usage, especially social interaction, may benefit the variables that negatively affect Internet addiction such as loneliness [19-20].

In this study, the predictive relationships between loneliness and Internet addiction were investigated because of some conflicting results about the relationship between loneliness and Internet addiction. However, another variable, which seems to be associated with both loneliness and Internet addiction, is mindfulness. It can be mentioned that mindfulness is linked with attention and awareness, where focus is effective, concentrated, and increased [21-23]. Also, mindfulness reaches a level high after a person's experience of an event, rather than staying stuck on the situation and experiences of the past and future, it lives by accepting in a caring way and it is said to focus on the following host $[24,25]$. On the basis of these mentioned characteristics of mindfulness, it is highly anticipated and logical to have a negative relationship with both Internet addiction and loneliness. As a matter of fact, there are studies showing that mindfulness is negatively related to Internet addiction and loneliness. For example, Arslan [26] reported that negative awareness is a negative relationship with the Internet dependence of mindfulness, in other words, the negative awareness of mindfulness of the Internet addiction. In a study in which the effect of a mindfulness-based program on gaming addiction was investigated, it was concluded that mindfulness helped to reduce the game addiction [27]. In another study, it was stated that mindfulness plays a regulatory role in the relationship between smartphone addiction levels of adolescents, depression, and anxiety [28]. In a similar study conducted with university students, it was reported that the levels of smartphone dependency of the individuals receiving mindfulness-based cognitive therapy decreased [29]. Mindfulness is also negatively associated with loneliness, as previously stated. For example, it has been reported that loneliness levels of students participating in the program at the end of an application program based on mindfulness, were significantly reduced compared to those in the control group [15]. Akin [30] stated that there is a negative correlation between mindfulness and loneliness. In another study, it was similarly mentioned that mindfulness practices could reduce the loneliness level of individuals [31].

The results of the studies mentioned so far show that Internet addiction is generally positively related to loneliness. Mindfulness is a variable with both Internet addiction and loneliness variable. However, it is mentioned in the literature that there are some conflicting results about the relationship between Internet addiction and loneliness, especially the effect of the Internet on loneliness and use of Internet in some cases may reduce loneliness. In this study, it is aimed to examine the predictive relationships between loneliness, Internet addiction, and mindfulness through the structural equation model. It is thought that the study may contribute to the literature in terms of having inconsistent results between Internet addiction and loneliness, and to reveal the importance of mindfulness in this relationship.

\section{Method}

\subsection{Structural Equation Modeling}

Structural equation modeling (SEM) is a statistical tool that enables the analysis of multivariate data. In addition, structural equation models go beyond ordinary regression models because they reveal hidden structures that the observed sets of variables can represent. Another important feature is that it gives a way to test the set of relationships between observed and hidden variables, even when experiments are not possible, and to allow the theory test. As a result, these methods are widely used in all social and behavioral sciences [32]. Therefore, in this study, structural equation model was used to determine the relationship between loneliness, Internet addiction and mindfulness.

\subsection{Working Group}

The study group consisted of students who were attending Gaziantep University in the fall semester of 2018-2019. The age of the participants in the study ranged between 17 and 39 years. A total of 507 people participated in the study, of which $352(69.4 \%)$ were female and 155 $(30.6 \%)$ were male. The mean age of the study group was $20.91(\mathrm{Ss}=2.85)$.

\subsection{Data Collection Tools}

In order to collect data, a demographic information form, the Mindfulness Scale, the Internet Addiction Scale, and the UCLA Loneliness Scale were used.

Mindfulness Scale: The Turkish adaptation study of the scale was developed by Brown and Ryan [21] and was conducted by [22] The Mindfulness Scale consists of 15 items and is a 6-point Likert scale. The scale shows a single factor structure. In order to determine the construct validity of the scale, both exploratory factor analysis and confirmatory factor analysis were used. The analyses 
showed that the single-factor structure of the Mindfulness Scale was appropriate. The factor loadings of the scale ranged from .48 to .81 and the test-retest correlation was found to be .86 . The internal consistency coefficient of the scale was reported as .80 . The results of the Turkish adaptation of the scale indicate that psychometric properties of the scale are also suitable for the Turkish language.

Internet Addiction Scale: The Turkish adaptation study of the Internet Addiction Scale was developed by Chen, Weng, Su, Wu, and Yang [33] and was conducted by Kesici and Şahin [34]. The scale consists of 26 items in total and is a 4-point Likert scale. The scale has five sub-dimensions in total. These include compulsive use, tolerance, time management, interpersonal and health problems, and withdrawal. The internal consistency coefficient was $.86, .91, .89, .91$ and .90 respectively. The test-retest reliability of the scale was calculated as .88 . These results indicate that the psychometric properties of the scale are also suitable for the Turkish language.

UCLA Loneliness Scale: The scale was developed by Russell, Peplau, and Ferguson [35]. The Turkish adaptation study of the 20-item solitude scale, which was developed by Russell, Peplau, and Cutrona [36], was conducted by Demir [36]. The test-retest reliability of the loneliness scale was found to be .94 and the internal consistency coefficient was reported to be 96 . The scores that can be taken from the scale vary between 20 and 80 . High scores from the scale mean that the level of loneliness is high.

\subsection{Process and Data Analysis}

In the data collection of the study, a questionnaire consisting of the demographic information form, the
Mindfulness Scale, the Internet Addiction Scale, and the UCLA Loneliness Scale were composed via Google Forms. An announcement was made to the students who were studying at Gaziantep University. A voluntary participation form was prepared at the beginning of the questionnaire, which explained the purpose of the study and informed the participants. The students voluntarily filled out the questionnaires after they gave their approval on the voluntary consent form. It took about 15-20 minutes to fill out the questionnaires. In the data analysis, the Pearson Product Moment Correlation Analysis Technique was used with the help of SPSS 23 to determine the relationships between the variables. After the correlation analysis, the aim was to determine the predictor relations between the variables by means of AMOS 24.

\section{Results}

The results of the statistical analyses performed in this part of the study are given. Firstly, the normal distribution of the variable scores used in the study was examined. The skewness and kurtosis coefficients of the variables used in the study are shown in Table 1.

When mindfulness, isolation, and where the mean and median values for the Internet addiction dimensions are close to each other, the distortion kurtosis is seen in the range of -1 and +1 for all variables. The results obtained from this research also show that they are close to a normal distribution of scores on the variables and may be used in parametric tests [38]. There are also studies which indicate that the distribution of the size of the sample will approach normal levels [39]

Table 1. Mean, mode, median values, and skewness coefficients of the variables included in the study

\begin{tabular}{|c|c|c|c|c|c|c|c|c|}
\hline Variables & $\boldsymbol{X}$ & $\mathbf{s d}$ & mode & Median & Distortion & SH $_{\mathbf{C K}}$ & stickiness & SH $_{\mathbf{B K}}$ \\
\hline Mindfulness & 58.10 & 12.40 & 56.00 & 58.10 & -.251 & 108 & 009 & .217 \\
\hline Loneliness & 40.68 & 7.49 & 35.00 & 40.00 & 444 & 108 & -.264 & .217 \\
\hline Compulsive Usage & 11.79 & 3.95 & 11.00 & 11.00 & 204 & 108 & -.576 & .217 \\
\hline Tolerance & 9.89 & 3.40 & 10.00 & 10.00 & -.006 & 108 & -.723 & .217 \\
\hline Time management & 9.37 & 4.06 & 5.00 & 9.00 & 776 & 108 & -206 & .217 \\
\hline Interpersonal and Health Problems & 12.76 & 5.31 & 7.00 & 12.00 & .858 & 108 & 127 & .217 \\
\hline Back off & 10.95 & 4.10 & 5.00 & 11.00 & 340 & 108 & -620 & .217 \\
\hline
\end{tabular}


Correlation analyses were performed to determine the relationships between the variables in the study. As shown in Table 2, there is a low negative correlation between loneliness and mindfulness $(\mathrm{r}=-.258, \mathrm{p}<.001)$. Similarly, it is observed that Internet addiction of mindfulness has a significant negative correlation with compulsive use, tolerance, time management, interpersonal and health problems, and withdrawal dimensions respectively $(\mathrm{r}=$ $-.186, \mathrm{p}<.001 ; \mathrm{r}=-.162, \mathrm{p}<.001 ; \mathrm{r}=-.211, \mathrm{p}<.001 ; \mathrm{r}=$ $-.229, \mathrm{p}<.001 ; \mathrm{r}=-.198, \mathrm{p}<.001)$. The Internet dependence of loneliness was found to be negatively correlated with compulsive use, tolerance, time management, interpersonal and health problems, and withdrawal dimensions $(\mathrm{r}=-.120, \mathrm{p}<.01 ; \mathrm{r}=-.127, \mathrm{p}<$. $01 ; \mathrm{r}=-.203, \mathrm{p}<.001 ; \mathrm{r}=-.251, \mathrm{p}<.001 ; \mathrm{r}=-.147, \mathrm{p}$ $<.01)$.

In order to determine the predictor relationships between loneliness, mindfulness, and Internet addiction, analyses were carried out with the help of structural equal modeling. Before starting the analysis, a subtle variable named 'Internet addiction' was created by using five sub-dimensions of Internet addiction and the analyzation process was continued this way. It was observed that the fit indices of the model that were initially created were not fully suitable. The fit indices of this model were found as $\mathrm{CMIN} / \mathrm{DF}=14.75, \mathrm{p}<.000, \mathrm{CFI}=.904, \mathrm{GFI}=.896$, $\mathrm{AGFI}=.777, \mathrm{NFI}=898, \mathrm{TLI}=.844, \mathrm{RMSEA}=165$. When the modifications that can be made are examined, it is seen that covariance established between Internet variance error management and time management and interpersonal and health problems dimensions will improve the model. After the modification, it was determined that the fit indices of the model became good and the model could be accepted. The fit indices of the obtained model are shown in Table 3 and the model tested is shown in Figure 1.

Table 2. Relations between mindfulness, loneliness and Internet addiction

\begin{tabular}{|c|c|c|c|c|c|c|c|}
\hline & $\mathbf{1}$ & $\mathbf{2}$ & $\mathbf{3}$ & $\mathbf{4}$ & $\mathbf{5}$ & $\mathbf{6}$ & $\mathbf{7}$ \\
\hline $\mathrm{M}$ & - & & & & & \\
\hline $\mathrm{L}$ & $-258^{* * *}$ & - & & & & \\
\hline $\mathrm{CU}$ & $-186^{* * *}$ & $.120^{* *}$ & - & & & \\
\hline $\mathrm{T}$ & $-162^{* * *}$ & $.127^{* *}$ & $.765^{* * *}$ & - & & \\
\hline $\mathrm{TM}$ & $-211^{* * *},$. & $.203^{* * *}$ & $.624^{* * *}$ & $.675^{* * *}$ & - & \\
\hline $\mathrm{IHP}$ & $-229^{* * *}$ & $.251^{* * *}$ & $.581^{* * *}$ & $.583^{* * *}$ & $.778^{* * *}$ & - \\
\hline $\mathrm{W}$ & $-198^{* * *}$ & $.147^{* *}$ & $.755^{* * *}$ & $.704^{* * *}$ & $.653^{* * *}$ & $.598^{* * *}$ & - \\
\hline
\end{tabular}

Note. M: Mindfulness, L: Loneliness, CU: Compulsive Use, T: Tolerance, TM: Time Management, IHP: Interpersonal and Health Problems, W: Withdrawal

$* * \mathrm{p}<.01 . * * \mathrm{p}<.001$

Table 3. Conformity indices for structural equation model

\begin{tabular}{|c|c|c|}
\hline Model Integration Indexes & Obtained Compliance Values & Acceptable \\
\hline CM / DF & 3.783 & $0<\mathrm{X}^{2} / \mathrm{sd}<5$ \\
\hline CFU & 982 & $0.90 \leq \mathrm{CFI} \leq 1,0$ \\
\hline AGFI & .943 & $0.90 \leq \mathrm{AGFI} \leq 1,0$ \\
\hline GFI & .976 & $0.90 \leq \mathrm{GFI} \leq 1,0$ \\
\hline NFU & .976 & $0.90 \leq \mathrm{NFI} \leq 1,0$ \\
\hline TLI & 982 & $0.90 \leq \mathrm{TLI} \leq 1,0$ \\
\hline RMSEA & .074 & $0.00 .10 \mathrm{RMSEAMS} 0.10$ \\
\hline
\end{tabular}




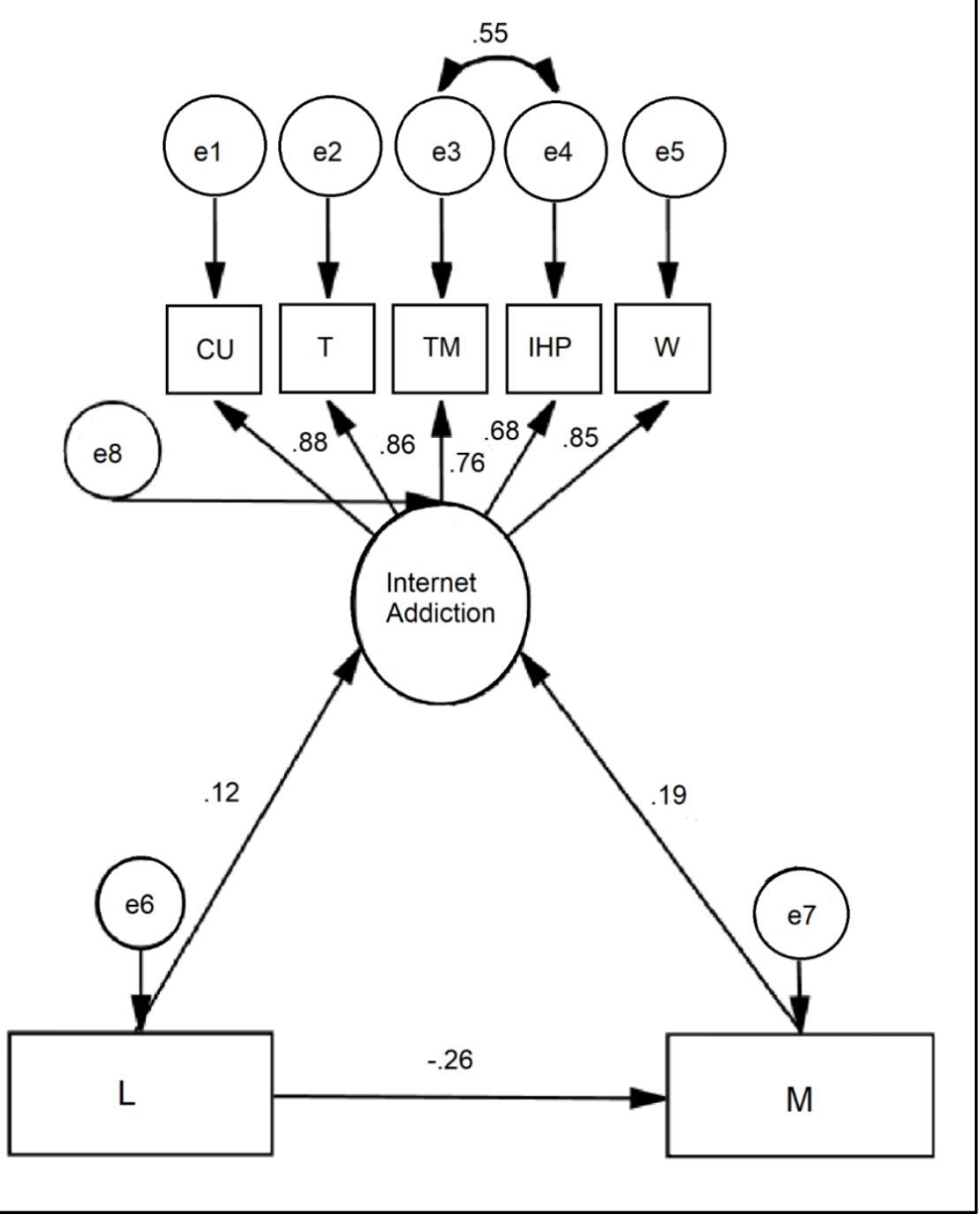

Figure 1. Structural equation model for relationships between loneliness, conscious awareness and Internet addiction

Table 4. Structural equation model for predictive relationships between loneliness, mindfulness, and Internet addiction

\begin{tabular}{|c|c|c|c|c|c|c|}
\hline Arguments & Dependent Variables & Total Impact & Direct Impact & Indirect Impact & S. H. & $\begin{array}{c}\mathrm{t} \\
\text { value }\end{array}$ \\
\hline Loneliness & Mindfulness & -.26 & -.26 & 0 & 07 & $-6.00^{* * *}$ \\
\hline Loneliness & Internet addiction & 17 & .12 & .05 & 02 & $2.62^{* *}$ \\
\hline Mindfulness & Internet addiction & -19 & -19 & .0 & 01 & $-4.07^{* * *}$ \\
\hline
\end{tabular}

$* * \mathrm{p}<.01, * * * \mathrm{p}<.001$

When the shape of the structural equation model is examined, it is seen that the loneliness variable affects the conscious variable. The total effect of loneliness on mindfulness was found to be at the level of $26(t=-6.00 p$ $<.001$ ). According to the relationship between loneliness and Internet addiction, it was determined that loneliness predicted Internet addiction positively and the total effect on Internet addiction was found to be $17(\mathrm{t}=2.62 \mathrm{p}<$. $01)$.

When the relationship between mindfulness and Internet addiction is examined, it is seen that mindfulness predicts Internet addiction negatively and its effect on
Internet addiction is at the level of $19(t=-4.07 p<.001)$. Besides, it has been determined that loneliness affects Internet addiction through the mindfulness variable and $\beta$ $=.05$ an indirect effect of loneliness on Internet addiction. In light of these findings, it can be said that the level of mindfulness of individuals with increasing loneliness decreased and Internet dependency levels increased. The fact that the loneliness variable has an indirect effect on Internet addiction through mindfulness can be explained by the fact that individuals with high awareness level, are less likely to be addicted to the Internet. As such, mindfulness plays an important role in the relationship 
between loneliness and Internet addiction.

\section{Discussion}

The interpretation and discussion of the results of the statistical analyses performed in this section of the research are given. The aim of this study was to investigate the predictive relationships between loneliness, Internet addiction, and mindfulness. According to the results of correlation analysis to determine the relationships between the variables, it was concluded that mindfulness is negatively related to all sub-dimensions of Internet addiction and loneliness in accordance with the literature. When the correlation analysis between loneliness and Internet addiction was examined, it was determined that loneliness was related to all aspects of Internet addiction with positive direction. It can be said that this finding is consistent with many research results in the literature $[11,13,40]$.

With the results of the structural equation model, which examines the predictive relationships between loneliness, Internet addiction, and mindfulness, it was determined that loneliness predicted Internet dependency positively in the model. Again, according to the model created, it was found that loneliness predicted mindfulness negatively. It also was concluded that mindfulness predicted Internet addiction negatively. Furthermore, Internet addiction isolation according to the generated structural equation model not only directly affects the mindfulness variable but also indirectly affects it as well, i.e. isolation and the mindfulness variables in the relationship between Internet addiction was determined to be the indirect effect tool. Kim, LaRose, and Peng [11] stated compulsive Internet use in the solitude of the study procedure. Loneliness predicted compulsive Internet use in a positive way reported by Zhang et al. [15]. It can be said that the results of this study support the findings obtained in this study.

It seems quite logical that the loneliness of mindfulness is negative. Individuals with high levels of loneliness may not have the characteristics of individuals with a high level of mindfulness, that is, instead of living in the present moment, it may be thought that they can focus on past or future experiences by focusing on lonely situations and thus, may lead to more Internet use [3]. Another explanation of this situation can be done as follows: People have a number of psychological needs [41] people with a high level of mindfulness and sustaining their lives by giving attention to a main focal point. It may be thought that they may be suitable adult-thinking. It can be said that even if a person with a high level of mindfulness uses the Internet and even if the use of the Internet exceeds the normal limits, they can use the Internet more effectively and appropriately than the individuals with low awareness. Therefore, they may not develop dependency. The results of the research, which mentioned that Internet addiction has a negative relationship with mindfulness, support this idea [26, 28]. On the other hand, as the level of loneliness of a person with a high level of mindfulness is not low, they may continue their life as a functional Internet user instead of developing dependency by turning to the Internet for solitude reasons.

However, it can be said that an individual with a high level of loneliness, who experiences loneliness, and who has previously expressed and that their mindfulness may be lower as reported in the findings of this study. A person with low mindfulness and loneliness can seek to find a solution in the virtual world by addressing the Internet in order to overcome this loneliness and to meet their psychological needs. Especially after experiencing a decrease in loneliness levels upon using the Internet, in this case it can serve as a reinforcement mission on the person and the award that is received as a result regarding lonely thoughts can develop dependency by turning again and again to using the Internet. It can be mentioned that the use of the Internet as an escape point for individuals who have social isolation and whose happiness is low [42] can be used as an escape point even if the use of Internet does not cause any significant decrease in the level of loneliness in the person.

However, in literature as in expression $[16,18]$ inter reduction of loneliness levels with online social support of individuals using social media tools on the Internet, is also seen as a possibility — but the loneliness results obtained in this study on Internet addiction is a variable that increases. Besides, the question of whether loneliness or Internet addiction is caused by Internet addiction or loneliness may be a matter of discussion. The results of the research show that people with high levels of loneliness are likely to be addicted to the Internet have already been mentioned before, and the results of this research move in this direction. However, individuals with addictive levels of Internet use on any other grounds are likely to experience withdrawal and tolerance developing over time; this should also be considered. The positive correlation between the withdrawal subscale of the Internet addiction scale and loneliness, albeit at a low level, supports this idea.

\section{Result}

As a result, it is concluded that loneliness is a predictor of Internet addiction in this research and that loneliness predicts mindfulness negatively according to the model tested with the help of the structural equation model. However, mindfulness predicts Internet addiction in a negative way. In addition, it is concluded that negativity affects Internet addiction indirectly via the mindfulness variable and that mindfulness plays an important role in the relationship between loneliness and Internet addiction. Based on the findings obtained in this study, it can be 
thought that studies related to loneliness levels of individuals may prevent Internet addiction. It can be stated that the practices and therapies to be carried out based on mindfulness will decrease the loneliness levels and Internet dependency levels of the individuals, especially in the literature. It can be mentioned that the studies carried out in this direction can start to use functionally instead of using the Internet in a more positive way by affecting the lives of university students.

\section{REFERENCES}

[1] Hawi, N., \& Samaha, M. (2019). Identifying commonalities and differences in personality characteristics of Internet and social media addiction profiles: Traits, self-esteem, and self-construal. Behaviour \& Information Technology, 38 (2), 110-119.

[2] Young, KS (1998). Internet addiction: The emergence of a new clinical disorder. Cyberpsychology \& Behavior, 1 (3), 237-244.

[3] Caplan, SE (2006). Relations among loneliness, social anxiety, and problematic Internet user. CyberPsychology \& Behavior, 10 (2), 234-242.

[4] Yao, MZ, \& Zhong, ZJ (2014). Loneliness, social contacts and Internet addiction: A cross- lagged panel study. Computers in Human Behavior, 30, 164-170.

[5] Zhang, N., Fan, FM, Huang, SY, \& Rodriguez, MA (2018). Mindfulness training for loneliness among Chinese college students: A pilot randomized controlled trial. International Journal of Psychology, 53 (5), 373-378.

[6] Young, KS, \& Rogers, RC (1998). The relationship between depression and Internet addiction. Cyber psychology \& Behavior, 1 (1), 25-28.

[7] Gunay, O., Ozturk, A., Arslantas, EE, \& Sevinc, N. (2018). Internet addiction and depression levels in Erciyes University students. Dusunen Adam the Journal of Psychiatry and Neurological Sciences, 31, 79-88.

[8] Jang, KS, Hwang, SY, \& Choi, JY (2008). Internet addiction and psychiatric symptoms among Korean adolescents. Journal of School Health, 78 (3), 165-171.

[9] Ebeling-Witte, S., Frank, ML, \& Lester, D. (2007). Shyness, Internet use, and personality. Cyber Psychology \& Behavior, 10 (5), 713-716.

[10] Kim, HS, Choi, YH, \& Yoo, SJ (2010). The study on the relations among ego-identity, stress, and Internet addiction in high school students. Journal of Korean Academy of Psychiatric and Mental Health Nursing, 19 (2), 173-185.

[11] Kim, J., La Rose, R., \& Peng, W. (2009). Loneliness as the cause and the effect of problematic Internet use: The relationship between Internet use and psychological wellbeing. Cyber Psychology \& Behavior, 12 (4), 451-455.

[12] Moody, EJ (2001). Internet use and its relationship to loneliness. Cyber Psychology \& Behavior, 4 (3), 393-401.

[13] Pontes, HM, Griffiths, MD, \& Patrão, IM (2014). Internet addiction and loneliness among children and adolescents in the education setting: An empirical pilot study. Aloma: Revista de Psicologia, Ciències de l'Educació i de l'Esport, 32 (1), 91-98.

[14] Özdemir, Y., Kuzucu, Y., \& Ak, Ş. (2014). Depression, loneliness and Internet addiction: How important is low self-control? Computers in Human Behavior, 34, 284-290.

[15] Zhang, S., Tian, Y., Sui, Y., Zhang, D., Shi, J., Wang, P., \& Si, Y. (2018). Relationships between social support, loneliness, and Internet addiction in Chinese postsecondary students: A longitudinal cross-lagged analysis. Frontiers in Psychology, 9.

[16] Shaw, LH, \& Gant, LM (2002). In defense of the Internet: The relationship between Internet communication and depression, loneliness, self-esteem, and perceived social support. Internet Research, 28 (3), 157-172.

[17] Morahan-Martin, J., \& Schumacher, P. (2003). Loneliness and social uses of the Internet. Computers in Human Behavior, 19 (6), 659-671.

[18] Scott, GG, Boyle, EA, Czerniawska, K., \& Courtney, A. (2018). Posting photos on Facebook: The impact of narcissism, social anxiety, loneliness, and shyness. Personality and Individual Differences, 133, 67-72.

[19] Nowland, R., Necka, EA, \& Cacioppo, JT (2018). Loneliness and social Internet use: Pathways to reconnection in a digital world? Perspectives on Psychological Science, 13(1), 70-87.

[20] Simpson, A., Clarke, S., Sarkic, B., Smullen, JB, \& Pereira, CJ (2018). Internet usage and loneliness in older hearing aid wearers. Canadian Journal of Speech-Language Pathology and Audiology, 42 (1), 69-79.

[21] Brown, KW, \& Ryan, RM (2003). The benefits of being present: Mindfulness and its role in psychological well-being. Journal of Personality and Social Psychology, 84 (4), 822- 848.

[22] Özyeşil, Z., Arslan, C., Kesici, Ş., \& Deniz, ME (2011). Bilinçli Farkındalık Ölçeği'ni Türkçe ' ye uyarlama çalışması. Eğitim ve Bilim, 36 (160), 224-235.

[23] Yalçın, SB, Kavaklı, M., Kesici, Ş., \& Ak, M. (2017). University Students' Early Maladaptive Schemas' Prediction of Their Mindfulness Levels. Journal of Education and Practice, 8 (20), 174-181.

[24] Özyeşil, Z., Deniz, ME, \& Kesici, S. (2013). Mindfulness and five factor personality traits as predictors of humor. Studia Psychologica, 55 (1), 33-45.

[25] Shapiro, SL, Carlson, LE, Astin, JA, \& Freedman, B. (2006). Mechanisms of mindfulness. Journal of Clinical Psychology, 62 (3), 373-386.

[26] Arslan, G. (2017). Psychological maltreatment, forgiveness, mindfulness, and Internet addiction Computers in Human Behavior, 72, 57-66.

[27] Li, W., Garland, EL, \& Howard, MO (2018). Therapeutic mechanisms of Mindfulness- Oriented Recovery Enhancement for Internet gaming disorder: Reducing craving and addictive behavior by targeting cognitive processes. Journal of Addictive Diseases, 1-9.

[28] Yang, X., Zhou, Z., Liu, Q., \& Fan, C. (2019). Mobile phone 
addiction and adolescents' anxiety and depression: The moderating role of mindfulness. Journal of Child and Family Studies, 1-9.

[29] Lan, Y., Ding, JE, Li, W., Li, J., Zhang, Y., Liu, M., \& Fu, H. (2018). A pilot study of a group mindfulness-based cognitive-behavioral intervention for smartphone addiction among university students. Journal of Behavioral Addictions, 7 (4), 1171-1176.

[30] Aki, A. (2010). Self-compassion and loneliness. International Online Journal of Educational Sciences, 2 (3), $702-718$.

[31] Rosenstreich, E., \& Margalit, M. (2015). Loneliness, mindfulness, and academic achievements: A moderation effect among first-year college students. The Open Psychology Journal, 8 (1), 138-145.

[32] Hox, J. J., \& Bechger, T. M. (1998). An introduction to structural equation modeling.

[33] Chen, SH, Weng, LJ, Water, YJ, Wu, HM, \& Yang, PF (2003). Development of a Chinese Internet Addiction. Chinese Journal of Psychology. 45 (3), 279-294.

[34] Kesici, S., \& Sahin, I. (2010). Turkish adaptation study of Internet Addiction Scale. Cyberpsychology, Behavior, and Social Networking, 13 (2), 185-189.

[35] Russell, D., Peplau, LA, \& Ferguson, ML (1978). Developing a measure of loneliness. Journal of Personality Assessment, 42 (3), 290-294.

[36] Russell, D., Peplau, LA, \& Cutrona, CE (1980). The revised UCLA Loneliness Scale: Concurrent and discriminant validity evidence. Journal of Personality and Social Psychology, 39 (3), 472-480.

[37] Demir, A. (1989). The validity and reliability of the UCLA Loneliness Scale. Journal of Psychology, 7 (23), 14-18.

[38] Uğurlu, CT (2013). Öğretmenlerin iletişim becerisi ve empatik eğilim davranışlarının çocuk sevme düzeyleri üzerine etkisi. Pegem Eğitim ve Öğretim Dergisi, 3 (2), 51-61.

[39] Elliott, AC, \& Woodward, WA (2007). Statistical analysis quick reference guidebook: With SPSS examples. London: Sage.

[40] Mahapatra, S. (2019). Smartphone addiction and associated consequences: Role of loneliness and self-regulation. Behaviour \& Information Technology, 1-12.

[41] Kesici, S. (2015). Psychological needs as predictors of human values in high school students. The Anthropologist, 19 (2), 499-506.

[42] Yalçın, SB, Ak, M., Kavaklı, M., \& Kesici, Ş. (2018). Mutluluğun önündeki engel: Erken dönem uyumsuz şemalar. Bilişsel Davranışçı Psikoterapi ve Araştırmalar Dergisi, 7 (1), 7-13. 